\title{
HRM in foreign affiliates: A multiple case study among Estonian affiliates of Finnish companies*
}

\author{
Ervasti Mia, Vesa Suutari**
}

The key question concerning the HRM in MNCs is the extent of global standardization versus localization of HRM-practices. The present study analyses whether the Finnish companies operating in Estonia apply a clear strategical approach to their IHRM and if so, what kind of approach (standardization versus localization) they have adopted across key HRMfunctions. The study followed a qualitative multiple case study approach. The results of the study showed that case companies did not have one clear approach to HRM in foreign affiliates in Estonia, i.e. those had not systematically standardized or localized all the HRM-functions.

Ein wichtiges Kriterium im Personalmanagement in multinationalen Unternehmen ist die Gegenüberstellung des Ausmasses der globalen Standardisierung im Vergleich zur Lokalisierung von HRM-Praktiken. Die vorliegende Studie analysiert, ob die finnischen Unternehmen in Estland eine klare Strategie im Hinblick auf ihr HRM verfolgen und falls ja, welche Art von Ansatz (Standardisierung oder Anpassung an örtliche Begebenheiten) sie für Schlüsselfunktionen im HRM genutzt haben. Die Studie basiert auf mehreren Fallstudien. Die Ergebnisse zeigen auf, dass die untersuchten Firmen keinen klaren Ansatz für das HRM in ausländischen Tochterfirmen in Estland haben, d.h. sie haben ihre HRM-Funktionen weder systematisch standardisiert noch lokalisiert.

Key words: HRM / MNC / Finland / Estonia / standardization / localization

\footnotetext{
Manuscript received: 08.08.03, accepted: 27.11 .03 (no revision)

** Ervasti Mia, Project Researcher, Department of Management, University of Vaasa. Main research interests: International HRM

Vesa Suutari, Professor, Head of Department, Department of Management, University of Vaasa. Main research interests: International HRM, global leadership, international careers, expatriate management, cross-cultural and comparative management. Corresponding address: Vesa.suutari@uwasa.fi
} 


\section{Introduction}

The increasing globalization of business is causing new pressures for HRM within MNCs. The effective management of human resources internationally is increasingly acknowledged as a key competitive advantage in international business (Edwards et al. 1996), and as a major determinant of success or failure in international business (Stroh/Caligiuri 1998). Of all the management domains, HR management is generally considered to be the most sensitive to local context (Gooderham et al. 1999). At the same time, there are strong pressures to adapt global strategies in many fields of industries. The realization of such strategies in turn typically require higher level of global integration of key HRM-processes. Thus, many MNCs have aimed at a higher level of integration of HRM practices, but such aims have faced the resistance due to the local culture, legislation and traditions (Lindholm et al. 1999).

There are different approaches to human resource management within MNCs which in turn are closely related to international strategies of the firm (see e.g. Dowling et al. 1999; Scullion 1999). Companies with an ethnocentric approach allow little autonomy to foreign affiliates and the major decisions are made in the headquarters. The key positions are fulfilled with the PNC nationals, i.e. expatriates. This naturally increases the use of home country approaches and practices in the foreign affiliates. Companies with polycentric approaches use totally different approaches: major decisions are made at foreign affiliates and key positions are typically filled with host country representatives. This leads to more localized solutions in the HRM. In addition, so-called regiocentric (areal strategy, structure, management and HRM) and geocentric approaches have been traditionally named.

According to Dowling et al. (1999) it is still fairly difficult to classify companies by a single approach since complexity of international operations creates pressures to make changes in basic approaches. The key question concerning the HRM in MNCs is still the extent of global integration (standardization) versus local responsiveness (e.g. Evans et al. 2002; Schuler et al. 1993; Lindholm et al. 1999). Typically, MNCs are seen as important disseminators of HRM practices and innovations in work organizations (Walch 2001). Empirically, the HRM practices that are found in MNC subsidiaries have been analysed in a number of studies (see e.g. Beechler/Yang 1994; Björkman/Ehrnrooth 1999; Ferencikova 2000; Rosenzweig/Nohria 1994; Scullion 1999; Walsh 2001). The most common studies in a CEE context are case studies of enterprises with FDI (Ferencikova 2000). They usually describe the changes, conflicts and results after the entry of a foreign investor into the previously state-owned company and also deal more or less with changes and conflicts in the HR area (e.g. Fogel 1995, Oddou/Mendenhall 1998). Nonetheless, there is a lack of empirical research which focuses on HRM in 
Western subsidiaries in Central and Eastern Europe (Björkman/Ehrnrooth 1999).

The CEE-context is an interesting area for an HRM study since effective HRM has been stated to be a key issue in the successful transformation of organizations in this context (e.g. Frederick/Rodrigue 1994; Gurkov/Kuz'minov 1995; Ivancevich et al. 1992; Puffer/McCarthy 1993; Suutari/Riusala 2001). A view one gets from the literature is that work morale and efficiency at the work place have traditionally been very low (e.g. Birch/Pooley 1995; Longenecker/Popovski 1994; Nasierowski 1996). A lack of independent initiative and quality thinking, and low ethical standards have also been frequently discussed (see e.g. Garrison/Artemyev 1994; Nasierowski 1996). Thus, studies of the management of business operations typically report difficulties concerning HRM-issues in CEE-contexts (see e.g. Suutari/Riusala 2000), and the foreign practices in HRM may lead to positive impact on productivity, no matter whether in production, commerce or services (Ferencikova 2000).

In the light of this background, the research objective of this pilot study was to analyse what kind of approach (standardization versus localization) the Finnish companies operating in Estonia apply to their IHRM and how consistent they are in their approach across HRM-functions. Before the presentation of the empirical research findings, some theoretical insights into localization versus standardization are presented.

\section{Understanding diversity: the local responsiveness}

There are different theoretical perspectives for understanding diversity: the cultural perspective, the institutional perspective, and the network perspective (Evans et al. 2002). According to the cultural perspective an individual goes through a socialization process into the culture, after which he interprets the outside world through the learned values and beliefs. Because of this, it is said that culture provides "the frame of reference" (Ronen 1986) or "mental programming" (Hofstede 1985) to the members of each culture. From this perspective, it has been argued that it is inappropriate to take management practices and theories from the culture in which they were developed and apply them to other cultures (see e.g. Bass/Burger 1979; Hofstede 1985). As Schneider (1988) argues, cultural differences should be taken into account, for example, in HRM because some of these practices may not be appropriate in the national culture wherein the subsidiary is embedded. An individual of a different culture may see these kinds of practices as unfair and illogical, and then the application of these practices may lead to unexpected consequences that hinder a subsidiary's performance. In the light of this, the role of crosscultural studies is seen to be to provide information for multinational companies which try to transfer organizational practices and policies from one country to 
another (see e.g. Bass/Burger 1979; Schneider 1988). From the cultural perspective, the fit between the organizational practices and the local culture is stressed and from this point of view it is argued that extensive global standardization of HRM-practices will not be an easy task. On the other hand, it has been argued that the cultural perspective underestimates the capacity of people from different cultures to adapt alien practices (Evans et al. 2002).

The institutional perspective implies a broader view of the national context; it stresses that the key to understanding business behaviour in different countries lies in the interrelationships between economic, educational, financial, legal and political systems (Evans et al. 2002). Thus, the extent to which MNCs implement innovative HRM practices is clearly affected by the nature and the character of the host country environment within which such firms operate (Walch 2001). For example, Ferner (1997) states that the relative stength or weakness of the host coutry's culture and insitutions, particularly legal framework, will exert a decisive influence on the ability of MNCs to import their own approches to HRM. In the area of HR, the industrial relations issues are a clear example of such HR issues as are subject to strong legal or customary regulation in the host country in which the subsidiary operates, so that the home country impact is likely to be less clear (Ferner/Quaintanilla 1998). On the other hand, systems such as management development and compensations systems are seen to be less regulated by national industrial relations systems and therefore more affected by the MNC host country effect (Rosenzweig/Nohria 1994).

The network perspective in turn stresses that MNCs are not only influenced by their origins and the norms in countries in which they operate: they are also pressures to conform with to international peers and competitors in the field (Evans et al. 2002; Kraatz 1998). On the other hand, other MNCs could rather be seen as sources of institutionalization pressures than as an additional perspective for understanding diversity.

Both the cultural perspective and the institutional perspective provide insights into the localization needs within the HRM-function; the network perspective in turn points out the role of interorganizational networks in diffusing organizational practices as well. All in all, the key reasons for a localization approach within HRM include issues such as being reponsive to the requirements of local authorities and public opinion, access to local networks of personal and business contacts, increased job and career opportunities for locals and thus a higher level of organizational commitment among locals, and lower labour costs among locals (Evans et al. 2002). Such reasons may have to be contrasted with the problems of finding local candidates with necessary competencies, developing them with adquate training practices and finally being able to keep them within the company later on. 


\section{Global strategies: toward increasing global standardizization of HRM}

Interest in a standardization approach has been recently increasing due to the globalization of the business. The global integration is becoming a competitive necessity in a number of markets in which decentralized strategies were dominant in the past (Evans et al. 2002). Johansson (2000) states that there are four groups of variables that propel companies towards globalization: markets, competition, cost and government (e.g. trade policies, technical standards). On the whole, the approach of the global strategy is evident in the literature, i.e. the term global strategy implies focus on similarities, standardization, homogenization, concentration, and coordination on a worldwide basis (Svenssons 2001). Brake (1999) specifies four main principles which are connected with a global approach: Integration (acts as a co-ordinated network), Flow (resources must be able to flow through the organization), Leverage (drive towards standardization and the reduction of unnecessary duplication), and Optimization (i.e. local responsiveness is balanced with global responsibility in order to produce the best results for the total organization).

There has also been criticism of the global strategy approach. The main weakness of global integration strategies is the potentially negative impact on the firm's ability to be responsive to local demands of customers, employees and other interest groups (Evans et al. 2002). It has been argued that the necessity of matching the global strategy with national responses is inevitable (Hammerly 1992), and that few companies lend themselves to 'naive' global strategies, since all strategies require some degree of adaptation to regional and national conditions (Segal-Horn 1996). Thus there has to be balance and harmony between the standardization versus the adaptation, and the homogenization versus the tailoring, of business activities (Svenssons 2001). In line with this, Black/Ulrich (1999) state that the first critical capability that enables firms to integrate global activities appropriately and also to separate and adapt local activities effectively is being able to determine what belongs to the core of the organization and what does not. Issues that belong to the core of a business generally relate to principles that give the firm its identity and issues which are important to customers. This core should be integrated and standardized throughout worldwide operations. According to Evans et al. (2002), global integration does not not mean centralization of all aspects of a company's operations, but may be limited to a particular product, function, or value chain segment. Thus, though adopting global strategies, the question of the extent of localization vs standardization of certain operations and HRM-functions still remains.

From the HR-perspective, a firm should thus consider the HR implications of its global strategies and recognize that people are a critical component of the implementation of such strategies (e.g. Dowling et al. 1999). In the 
globalization phase, a global human resource strategy that will put the right, competent people in the right place at the right time doing the right things needs to be developed in line with the global business strategy (Brake 1997; Odenwald 1993; Suutari 2002). Very often the major focus in the strategy process has been on strategy formulation, with very little thought given to the implementation phase. This has resulted in the failure of strategic planning at the operational level, where personnel policies play a central role in ensuring that the employees' work makes strategies materialize (Torraco/Swanson 1995). In line with this, the findings among top global HRM managers indicate that three aspects of HRM were seen to be critical to the MNCs success in the global areana: adaptation of flexiple management practices and policies worldwide (i.e a high enough level of localization of policies), the inclusion of the HRMfunction as a strategic partner in global business, and the development of global leaders (Stroh/Caligiuri 1998).

The situation has been stated to be very challenging for international HRspecialists since the process of increasing commitment to international activities brings the HR function closer to the strategic core of the business and also changes the scope and content of human resource management (Pucik 1992). Given the critical role of a company's global talent asset base, the role of HR must become more proactive and strategic - HR must become a fully integrated global business partner (Brake 1999). On the other hand, it has been seen that the greatest barrier to HR units becoming strategic on a global scale is their own lack of expertise of international business-related issues (Stroh/Caligiuri 1998). In all such discussion, the importance of a strategic approach to international HRM is stressed. By the concept of strategic international human resource management is meant HRM issues, functions and policies and practices that result from the strategic activities of MNEs and that impact on the international concerns and goals of those enterprises (Schuler et al. 1993). According to Black and Ulrich (1999), the role of the HR professional in delivering global strategy is to 1) raise, define, and clarify the capabilities required to win globally and 2) invest, design, and deliver HR-practices that ensure these capabilities. This in turn means a higher level of global integration of HRMpractices which are in a key role in building and sustaining key capabilities and related competencies of employees within the organization. On the other hand, this should include the idea that the best policies and practices may originate in countries other than the one where the headquarters is located (Stroh/Caligiuri 1998).

All in all, the literature on HRM in foreign affiliates emphasizes the importance of HRM issues in international operations. The literatue also identifies clear strengths and weaknesses concerning both the standardization and localization approaches and thus no 'best practice'-solutions, which would fit all situations, are available. Still, the move toward more standardized/globally integrated HRM solutions within MNCs seems to become a more typical solution than in 
the past though the empirical research which covers these issues is still very limited. Next, new qualitative pilot study evidence on international HRMapproaches applied among Finnish companies with affiliates in Estonia is provided.

\section{Methods}

The present study followed a multiple case study approach (Yin 1994) in which four Finnish owned MNCs with units in Estonia were the sites of the investigation. The MNCs were chosen for this study as they all were Finnish companies, operating in Estonia and with enough employees to have necessary experience of HRM practices.

The study consists of semi-structured interviews of CEOs and/or HR/administrative managers made in four Finnish subsidiaries located in Estonia. In addition, a variety of company documents were also obtained in order to increase the undersatnding of the case companies (e.g. annual reports, organizational charts, company newsletters, brochures, manuals and presentations). With one exception (an Estonian manager who had long-term HRM experience of the Finnish parent company), the interviewees were Finnish expatriates. All the interviewees thus had long and profound experience both from the Baltic countries and Finland. The interviews lasted between one and two hours and were recorded with permission of the interviewees.

The interview was divided into two sections, which were split up into different themes. In the first section the respondents were asked to describe their own career and position in the firm. They were also asked about key internationalization strategy issues such as decisions and developments that led to extending the operations to Estonia as well as about the implementation of the entry process. In most cases the interviewees already started to talk freely about related HRM issues, which were the main subject in the second section. The respondents were asked to describe HRM practices in their company (staffing, performance management, personnel development, rewarding systems and labour relations). They were also led to compare their own host country unit's HRM practices with the MNC's home country operations. The main objective of this study was to increase the knowledge of the degree of standardization and localization of HRM practices within the companies. Recording of the interviews was done with a dictating machine, except in one case where a video camera was used. The tapes were transcribed and after that the written transcripts were used in the analysis. The validity of the analysis was improved by letting the interviewees afterwards read the case descriptions / interview transcriptions and make the necessary corrections. The changed versions of the cases were sent to the interviewees again for checking. 
All case companies represented different business sectors. The MNCs were chosen for this study as they all were Finnish companies operating in Estonia and with enough employees to have necessary experience of HRM practices. A brief sketch of each MNC is provided in the following paragraphs.

Company A. The firm is a mobile operator, which concentrates on offering digital mobile communication services to private and corporate customers. Its subsidiary was established in 1994 and the network was opened commercially at the beginning of 1995. At the end of the year 2000, the number of personnel employed in Estonia was approximately 200 . The HR policy was mainly an attempt to emulate the Finnish parent with minimal modification. The net sales in 2000 were approximately 25 million euros, indicating a growth of 57 per cent compared with the previous year. At the end of the year 2000 the estimated number of mobile phone users in Estonia was 500000, of whom 130000 were customers.

Company B. The case company was a department store in Estonia which is owned by a Finnish retail trade company. The department store division employs 450 people in the department store in Tallinn in 2000. HR policy was mainly standardized in the company but the company has faced big challenges especially in personnel development. The Department Store Division sales inclusive of VAT were 712,7 million euros. The net turnover in 2000 was 599.1 million euros, up 6 per cent on the previous year. In Estonia, sales inclusive of VAT were 36 million euros and sales grew by 6.2 million euros or 21 per cent.

Company C. The company develops and produces customer-oriented services, systems and individual products to assist professional kitchens in the production of food and beverages. The rapid growth that began five years ago has continued. The company's net sales have almost tripled since 1995. The company had about 50 employees in Estonia. The company respects in HR policy the host country's history and culture.

Company D. The company operates on the energy sector. Its business covers the entire energy chain, from the production of oil, gas, power and heat to refining, distribution and marketing, and to energy-related engineering, operation and maintenance. It had over 500 employees in 2000 in Estonia. The company represents a different integrated Baltic aspect of HR policy. Group net sales totalled approximately 11 milliard euros and the operating profit was 906 million euros.

There are inevitably several limitations to the present study. First, the cases were not a statistical sample and second, the number of the cases was not large. Second, the number of interviews turned out to be smaller than originally planned since very few members of the organizations had relevant experience of the HRM questions both in Estonia and in the Finnish headquarters. On the other hand, the respondents were very experienced. Third, all the companies 
were Finnish, which should be taken into account when making generalizations on the basis of the findings.

\section{Results}

The presentation of the results will be made case by case in line with the case study approach. In the conclusions the case findings will be collected together in order to get a total picture of the extent of standardization vs localization of HRM practices across the HRM-funtions.

The first case company was named Company A. As a business area, telecommunication is pretty young. For this reason technical, service and administrational functions were mainly imported step by step from the Finnish parent company. Although the working model was imported, only some Finnish expatriates have been in Estonia. The company wanted to offer local employees opportunities to be promoted and has organized its own education for the managers. A local HR manager commented that "At first it was difficult to understand why everything was asked and why an agreement was made with the parent company. Now it is understandable that confidentiality is very important and the parent company gives us little by little more responsibility." Estonians wanted to find good and reliable employers who follow the legislation. Because of that employees were more stable in Estonia. According to the interview, staffing criteria and methods have been mainly standardized by the company. A manager commented, "There is no difference. At some point we even used the same Finnish consult office as the parent company. Nowadays we use the local consult, who tests by corresponding tests". At the beginning of the company's extension to Estonia, the telecommunication field was so young that it was extremely hard to find people who would be suitable for recruitment criteria. Telecommunication students have been recruited. They will get theoretical knowledge at a university and at the same time practical experience in the company. A manager stated, "Specialists in telecommunication have been difficult to find. Exactly the same thing was true of Finland before. We recruited directly from schools, because experts simply didn't exist". The biggest difference between those two countries was that in Estonia one had to make sure that the diplomas and working certificates were real. The HR manager commented, "In Finland references are asked for but here we are asking whether it is true that this person has worked or studied." Despite such minor amendments to the recruitment process, it was thus pretty much standardized.

Similarly, the aim of the performance management was to transfer the parent company's model from Finland to Estonia though some adjustments were made. An executive stated, "The development discussion model, the performance appraisal system and also the work satisfaction inquiry model are taken from Finland, but then we fitted them better to Estonian needs and also developed 
some of our own forms based on Finnish ones." Basically the company wanted to import a performance management system but it was not self-evident. From the company's point of view, a contract of employment has been more important in Estonia than in Finland and contracts influenced performance management a great deal. A manager commented that "In Finland those documents give a general view of the employees' working tasks. In Estonia a contract of employment is a big book where are detailed all of an employee's work tasks and rights. When work tasks change, pages will be added." Performance appraisal was based on those documents in Estonia, and they measured the performing of the detailed tasks. Also discussions between superiors and subordinates were a very important part of performance management. The HR manager commented that "The most important thing is how the performance management system is sold for the employees. Employees have to know what are the benefits of the system for both sides". All in all, the performance management was mainly standadized though some changes had been made in Estonia. On the other hand, the system hasn't been used for very long, which makes it pretty difficult to say whether they will be localized to a greater extent in the future.

Training and development have instead to a great extent been localized in the company. Rapid technical changes, the newness of the telecommunication area, and the employees' historical background affected personnel development a great deal. The HR manager stated that "We are mainly a service organization and unfortunately the customer service culture has always been very poor in Estonia." Understanding the importance of customers, service and selling was thus noticed as very important areas of development. The HR manager reported, "There is a clear difference between Finland and Estonia. Here we have been forced to use an enormous amount of time and energy to achieve better customer service skills." Positive feedback from the customers has raised the enthusiasm of employees to improve service skills. Managers have also informed all employees about the market situation and future plans, which strengthened the employees' feeling of having a share in a bigger entity. Some differences in the need for education between nationalities inside Estonia were also noted. It was stated that "Russians have noticed that they get better along in data administration. Education in Russian schools is more mathematical and language problems are smaller in that area." The market situation for three mobile operators was very hard. The competitive situation forced employees to produce more and to educate themselves all the time. According to the interview people were very eager to develop themselves in Estonia. About 60\% of the employees have academic degrees or are taking them. A manager stated, "There are so many students; they want to learn and develop themselves all the time. And most of the research work was done in their own organization, which means benefit to both parties". The company supported studies by making education contracts because the system of financial aid to students was very 
poor and fees were high in Estonia. When the situation was so different in comparison with Finland, very localized approaches were applied.

According to the interviewees, company's rewarding system has been standardized. A manager commented, "The rewarding system is mainly the same. Employees are rewarded monetarily or some other way for good performance and projects which are carried out. Profit rewarding systems are very similar in Finland and Estonia." On the other hand, it was noticed that "Estonians appreciate employers who are paying wages regularly and work in accordance with the legislation, which was self-evident to the Finns". Feedback culture was developed all the time in Estonia but it was not yet of as high a level as in Finland. It was commented that "young managers are not very good at giving feedback, when they were not used to getting it either". Another difference was that in Estonia education has had a very high social position. Thus, education was used more as a rewarding tool in the company's unit in Estonia than in Finland. In both countries leisure-time activities were supported as a rewarding system. Taken together, a farly standardized wage-system was applied and it was felt that it is pretty easy to move such a system from country to country, but the establishment of feedback culture takes much more time.

Labour relations were different in Finland and Estonia. A manager stated, "In Estonia there is no trade organization or union in the telecommunication field. Manufacturing firms have some kind of organized labour unions and lately authorities have started to pay more attention to occupational health service". Reducing the number of employees was more difficult in Estonia because of the labour legislation. The HR manager commented that "Here is also an office for problems at work. If the employer has infringed the legislation, it is possible to seek assistance from that office." Interviewees believed that it was better to solve problems inside the firm and maintain an open and trustful relationship between employer and employee. Due to the contextual differences, the labour relations function was localized to a large extent.

Company B started international operations in Russia in 1989. Interest in the markets in Estonia has been raised because there were no Western department store functions. Also experience from Russia, which is geographically near, created interest in Estonia. First they opened a store in 1993, but after good sales they opened a department store in 1996. According to the interview, the aim has been to standardize the criteria and methods used in staffing. An executive commented, "Most of the applicants came to look for employment personally in the department store like in Finland before. There is the Internet main channel for applications. The company will open the same channel later in Estonia and it is expected to be the most common channel to look for a job." Recruiting happened daily because of part-time workers but on the other hand the turnover of key persons was very small. The manager stated that "it was easy to find suitable persons, because most of the employees were students, who 
had good language skills and were well motivated". Most of the key-persons were trained as the host country unit's employees. The executive commented, "Only few people have come directly to a leadership position. It has been difficult to find Western thinking people who are committed to really working hard". The aim of the company was to find the right staff to fit in their organization culture. They have noticed that in most cases a local person is the best choice and they have had only few expatriates.

Performance management was also very standardized across units. The executive commented, "Every department has its own target and it is even divided into such small sections that every seller knows how much they should sell during the day." The best proofs of efficiency are team-related sales. The biggest problem was the measuring of sales absolutely and objectively. The manager stated, "A person who sits at a cash desk is not more effective than the person who really sells those jogging shoes". In some departments sellers even follow their sales daily. It was commented that "In Finland it is the same, some departments follow even daily sales". In any case paying the bonuses was based on group sales. As part of performance appraisal 'mystery shopping' (i.e. anonymous test customers) was used. Its aim is to measure objectively the quality of service.

The personnel's basic training and development practices were the same in both countries but in addition some key personnel development issues were localized to meet regional needs. Customer satisfaction was the central objective of trading in all its areas of business. In Estonia the biggest challenge was to develop customer service skills. The executive commented, "Customer service isn't characteristic of Estonians. Estonians are a bit withdrawn, a bit passive, they don't start talking whatever with a stranger". The company has really emphasized the training of customer service skills with the aim of getting sales persons from the cash desk to the customer service. The manager stated, "We have started to cooperate with a local training firm, which has given good results. We even planned competitions between departments, where good sellers have been given selling bonuses". Some differences between nationalities were discovered inside Estonian boarders. It was stated that, "Russians are more open and go more easily and naturally to customers while humbling oneself before customers doesn't belong to the Estonian national character." Some extra education was also been given about diminishing waste. Job rotation or working in supranational cooperation teams was also offered in Finland as well as in Estonia. All in all, the training and development were pretty standardized functions, but those were complemented with necessary additional training in the host country.

The rewarding system was very similar in Finland and Estonia, i.e. the system was fairly standized across units. The executive commented, "At seller level we have mainly the same kind of rewarding and bonus system. At key person level 
the compensating system is also pretty much the same". One difference is that in Estonia and Russia bonus was also paid for reducing waste. The manager stated, "We have here a tight follow-up and because of that, we have even smaller waste than in Finland". Salary was not the most important motivation tool, an employer's safety and stability were seen to be more important. There have also been attempts to encourage the personnel to make their stand. The executive stated, "When the personnel want, they can participate in developing the company and cooperation with Russia and Finland". Feedback giving was also seen as a part of the rewarding system. Differences were noticed in the taking of feedback between Estonians and Russians. The manager commented, "Russians are taking feedback well, things as things and not as personally as Estonians. Feedback has to be given smoothly so that those who get it don't take it too deep in their hearts".

According to the interview labour relations are handled locally in Estonia. Labour market unions already existed, but their working area was limited in Estonia. The manager stated, "There are no commonly applied work contracts, the company is responsible for taking care of things properly." It was still seen that Estonian legislation protected employee rights pretty well. For example, holidays were tightly set and employees' protection against arbitrary dismissal was similar to that in Finland.

Company C started operations in Estonia as early as the 1970's. The company worked through buying organizations until Estonia became independent and buying organizations broke up. The company established its own Ltd in the 1990 's but it was not able to work effectively. The manager stated that "We were lucky that we noticed that things are working only apparently. Physically the office was well equipped but e.g. no project information was saved in a computer. There was also a lack of understanding about the company's longterm aims". At first, the company thought that it would be possible to replace only part of the employees but this was found to be impossible and in 1995 the whole personnel was changed. Executives were not able to trust that know-how would stay inside the company because Estonia is a small country and culture where people have close relationships to old colleagues. The manager commented that "Reducing the personnel was pretty easy. There are not tight labour unions. Legislation has to be followed and salary for the term of notice has to be paid. It is also possible to negotiate with people and find a solution together".

Company $\mathrm{C}$ has had a clear personnel strategy from the beginning. It was stated that "Finnish know-how was the basis for development and investments in Estonia. It was important to find good local key persons and then it was possible to diminish the number of Finnish expatriates and at the end discharge them all." New personnel were in a key position when the company started to create new frames for business activities. The company used consults to find 
suitable personnel. The manager commented that "The situation was pretty different than now. The consult was easily able to find hundreds of people and then we just started to search for the potential candidates by traditional methods. It was a second birth of the company, when the personnel was totally changed. The atmosphere was cleared and the company rose in half a year to be the market leader in Estonia." Staffing operations have been much more carefully targeted later. Internet has become an important work-searching tool. According to the interview the staffing function was pretty standardized, i.e. recruitment and selection methods and the main criteria were the same in both countries.

The performance management system was fairly localized although every unit's strategic planning and budgeting were based on general targets, emphasis areas and development directions given by the parent company. The executive commented that "The unit's efficiency was measured through individual planning and budgeting. It strengthened the personnel's need to be responsible for operations of their own unit. It is difficult in Estonia because it is hard to find persons who are ready to take the responsibility. People are used to getting orders from executives and collectively fill those needs". About the personnel appraisal system the manager stated that "In Finland both collective and individual targets are used. Every person's targets are tied up with the salary and bonus system. We haven't adopted the same personnel appraisal system in Estonia, because I believe it causes the wrong kind of competition. Here we use collective targets. If the whole team reaches the target everyone gets a bonus". Also PM discussions were not used in the same way as in Finland. In that way, performance management was localized in order to fit in with the local special requirements. For example, the aim was to strengthen the personnel's willingness to take responsibility. At the same time, the company still wanted to maintain traditional collective ways of working, because of the effectiveness of such practices in Estonia.

According to the interviewee, there had been two key groups in developing the personnel: expatriates and local training personnel. It was commented that "Expatriates should be the trainers of local personnel in the beginning. They are business field experts. Unfortunately it's rare that they are experts in handling people from a different culture." Secondly, it was commented that "Training of the local staff starts from the people with suitable education and the right attitude". At first, people were trained to understand the company's business culture and environment. After that, the focus was turned to personal professional skills and knowledge. It was stated that "When you find the right personnel which wants to learn and change, they will develop very fast. The right key persons can then sell the reform to other employees". The company has developed and develops training and development, which fits especially Estonian circumstances. The target was to develop inside company training, of which the host country organization takes care. The main topics were the 
strengthening of the service-minded attitude and willingness to take personal responsibility. Also language demands were high in Estonia; four languages might easily be demanded. Job rotation was not considered a good training method. All in all, due to the local requirements, the training and development functions were pretty localized. Still, the role of expatriates was also stressed in training.

A rewarding system was standardized in Company $\mathrm{C}$, but the perceived value of monetary rewards was seen to be different in Finland and Estonia. The manager stated that "Money is a good motivation tool in Estonia, because here working is really profitable. The salary level is lower, but also the tax percentage is low and fixed. The more you work the more you have money to spend". The monetary rewarding system is based on fixed salary, monthly selling provision and year bonuses in both countries. The importance of bonus was bigger in Estonia, because in Finland taxation was much higher. The manager commented that "It makes sense to work the whole calendar year in Estonia. If an employee is considering a new job, the new salary's ability to compensate for the year bonus has to be counted". In both countries it was important to pay attention to people. The manager stated that "It is important to pay attention to things which are important for local culture e.g. in Estonia birthdays and education possibilities. In both countries employees are rewarded for goals achieved together. Unfortunately obstacles to rewarding are high costs and taxation in Finland".

Labour relations were not perceived to be a difficult issue to handle in Estonia. The manager stated that "If a firm follows the Finnish labour legislation in Estonia, it will succeed well. Of course there were some differences e.g. the number of children influences vacations etc. As long as you are on the right side of the law, the risks are not much bigger than in Finland." The biggest problems were faced in the interaction with local authorities. The manager commented that "The role of local authorities changes at last, the power they are using will become lower little by little. Already the understanding of the language in bureau is one problem but compared to that, corruption is an even hugher problem. When we faced it, we decided that we would have time to wait and not foul our hands with it, because you can't wash them clean any more." The crisis in Russia made the situation worse, but the reasons behind the corruption were actually pretty human. The authorities were afraid of a collapse of the economy and losing their jobs. All in all, the company followed pretty much the Finnish practice, i.e. the approach was fairly standardized.

The background of Company D differs from other case companies. The joint venture project started at the end of the 80's. The Finnish part invested in Western technology, marketing and know-how in joint venture in Estonia and the local partner invested in sites and petrol stations. The joint venture was changed later to become a wholly Finnish-owned company. The oil business 
activities were at last in Finnish hands in 1997, but the past had already had a remarkable influence on HRM. The executive stated, "We had a joint venture and local partners tried to find skilled labour here and we brought key persons from Finland. Then we started to learn how we could work together". The affiliate in Estonia has had plenty of expatriates but the long-term target has been diminishing the number of them and reserving key positions for local people. "It was noticed that foreigners couldn't sell here from door to door or business to business. It is more important to have expatriates who understand core business than ones who have the ability to speak local languages. After some years we will have only a small organization in Finland which understands Baltic issues, not expatriates in Estonia any more." Concerning staffing, they have done only some local operations. The manager stated that "We can operate more or less with the same personnel. In most cases we have filled new positions from the inside". The manager commented about used criteria and methods that "We got most employees in joint venture time and at that time here were no consults or other services." After the interview the company will be faced with a diminishing number of employees. The manager stated that "Socialism was a perfect system on paper and the protection of the employees was good; it will still be very difficult to reduce personnel. Baltic labour legislation is hard and it includes sanctions." Due to the joint venture background, the recruiting has been a rather localized function. The manager stated that "Right now our companies in all Baltic countries look different. The Estonian unit looks like my ways of doing things and other Baltic units work the same way as my colleagues. Now we are trying to make them more similar, which is challenging".

Focusing on the Baltic region as a whole has risen as an important topic in Company D and it doesn't concern only staffing. The manager commented that "We try to take care of three countries as if they were one country and it is always also a question of efficiency." Within the performance management system the focus was on the economic targets in the unit level. The manager stated, "One basic difference between companies in Finland and in the Baltic countries is size. Although we are smaller, we make budgets individually and have the same demands and criteria as companies in Finland". Performance management has changed much in the last five years. Earlier the role of specific job decriptions was more central when measuring performance. It was commented that "People were used to the Russian system, which had very specific job descriptions. Now in this model, which is used in the Nordic countries, it is only suggestively said which are the employee's work tasks and together as team we had to get all things done". The goal has thus been to move to a more standardized performance management system across units.

The level of education was seen to be traditionally high in Estonia and people were seen to be eager to educate themselves further. The interviewee stated that, "It is very common for people to work during the days and study for a 
university level at night and weekends". Estonian society has changed tremendously. It was commented that "Estonia has changed in five years as much as other countries in 20-30 years. These people haven't gone trough all transition phases, they have moved directly from the Soviet system five steps straight up". It was seen that in such a situation it is more important in the beginning to learn internal business ideas and practices than to study more general- level theories. At the beginning Company D sent people from the Baltic countries to Finnish units to learn, but then it was noticed that Finland is too different a place to work in. The executive commented that "We started to bring experts here. They were experts with an understanding of the Baltic background." The idea was again to manage the Baltic operations as a whole. In addition, job rotation was used in order to give employees the possibility of learning new issues and thus of being more ready for future challenges. In development the employees' own efforts to educate themselves was a benefit.

According to the interview, the rewarding system was mainly standardized across units in Company D, although there were some small differences. The manager stated that "The basic outline has been that we have a competitive rewarding system but we are not changing it often. It gives the employees a basic feeling of security." During the last few years the company has used a partial incentive and bonus system. The executive commented that "Building the bonus-systems needs much work. How big are the efforts? I believe that simple is beautiful. I hope that we are not creating such complicated systems that all our time goes to planning." According to the interview, giving feedback is a very important part of a rewarding system. It was said that "People in Estonia expect more feedback than in Finland. People in Finland feel embarrassed even by positive feedback, but here people need it and take it well".

According to the interviewee, labour relations were very much tied to company in Estonia, i.e. localized. The manager stated that "Under Soviet trade unions, employers' and employees' federations had a remarkable position in society. When the Soviet Union collapsed, the unions lost their position but they still exist. Now new labour unions are following the unions' actions and position in surrounding countries and then they will slowly get some role in Estonia again".

\section{Conclusions}

The present study reported findings from a pilot study on HRM in Finnish owned foreign affiliates in Estonia. Table 1 provides a comparison of the MNC approaches concerning five key HRM functions. After the table, the cross-case analysis of HRM functions is briefly made.

In three case companies of four the staffing practices and methods were fairly standardized, i.e. similar methods were used in Estonia as in the home country 
units. The most standardized criteria and methods were used by Company B. The company has coherent firm culture and clear staffing principles which were followed in both countries. In the case of Company A, the difficult staffing situation of the business area was emphasized. The telecommunication field is so young that telecommunication firms had created new ways of recruiting new staff in Finland too. The staffing function was pretty standardized in Estonia and the parent company was kept as a predecessor whose operation models were good to follow. The more traditional manufacturing firm Company $\mathrm{C}$, has nowadays a pretty standardized staffing function, though at the beginning of the Estonian operations things were a little bit different. The only company which used more localized approaches was case company D. The key reason behind this difference was the joint venture background due to which the local partner chose personnel. The Finnish partner had practically no chance of influencing the matter. In later phases only very few recruitments were made.

Table 1. A comparison of the MNC approaches concerning five key HRM functions

\begin{tabular}{|l|c|c|c|c|c|}
\cline { 2 - 6 } \multicolumn{1}{c|}{} & Staffing & $\begin{array}{c}\text { Performance } \\
\text { Management }\end{array}$ & $\begin{array}{c}\text { Training \& } \\
\text { Development }\end{array}$ & Rewarding & $\begin{array}{c}\text { Labour } \\
\text { Relations }\end{array}$ \\
\hline Comp. A & Standardized & Standardized & Localized & Standardized & Localized \\
\hline Comp. B & Standardized & Standardized & Localized & Standardized & Localized \\
\hline Comp. C & Standardized & Localized & Localized & Standardized & Standardized \\
\hline Comp. D & Localized & $\begin{array}{c}\text { Standardized/ } \\
\text { (Regional) }\end{array}$ & $\begin{array}{c}\text { Localized/ } \\
\text { Regional }\end{array}$ & Standardized & Localized \\
\hline
\end{tabular}

As in the case of staffing, three companies out of four used fairly standardized performance management systems across units. The purest standardization approach was represented by Company B: measuring tools and tools tied to rewarding systems were highly standardized. The only exception to standardizing was stressing the reduction of waste; it was appreciated more than in Finland. The performance management system was fairly standardized across units also in Company A since personnel appraisal methods, which functioned well in Finnish units, were applied in Estonia. Still, minor modifications were made, for example, since employment contracts were still in a fairly central role in performance management in Estonia. The case was very similar in Company $\mathrm{D}$ though the situation was under change since the aim of the firm was to move toward Baltic approaches. The most localized approach was represented by Company C. In the Estonian unit collective targets were stressed while in Finland individual targets and their supervision were emphasized. Estonians were not considered to be ready for individual evaluation and Finnish style of perfomance discussions because of historical reasons.

In the case companies a localized approach to training and development was dominating due to the context-related training needs. Although the business areas were different, all companies stressed development, fitted to local needs. 
In all case companies the Estonians' positive attitude to education was stressed. This has also been noticed in former studies in Estonia (e.g. Tulisalo et al. 1994; Üksvärav et al. 1993). Case companies emphasized different areas of development but one common area of development was customer service skills. In spite of their desire to learn, it was sometimes hard for employees to adopt adquate sevice attitude to customers. The approach taken by Company D was to some extent different since in that case the company aimed to develop regional development approaches for the whole Baltic area.

Rewarding was pretty standardized across countries in all case companies. Especially monetary rewarding systems were imported from the parent company. Transferring the monetary rewarding system was also considered to be pretty easy to carry out. In former studies the importance of money as a motivation tool in Estonia was stressed (Tulisalo et al. 1994). This appeared in the present study also, i.e. monetary rewards were found to be effective in Estonia. On the other hand, that interest had to be aroused by other methods such as feedback. Establishing such feedback system was found to be more difficult, because it was closely tied to culture.

All in all, the study showed that the case companies did not have a clear selected approach to HRM in foreign affiliates in Estonia, i.e. those had not systematically standardized or localized all the HRM-functions. Rather different approaches were used across HRM functions within the same companies. Still, some clear diffences could be found within companies. For example, one of the companies was clearly aiming at standardization when possible, while another one was moving toward a regional approach to HRM.

Similarly, no dominating approach could be found in most of the HRMfunctions, i.e. within the most HRM-functions at least one of the case companies had applied a different approach than the others. This indicates that in addition to the analysis of national cultures / contexts as entities we should focus as well on differences within fields of industries and within companies to fully understand the factors behind standardization vs. localization decisions. In addition, the field would benefit from the analysis of the effectiveness of such different approaches in combination with the contextual analysis in order to understand when different approaches are efficient and when they are not. The strengths and weaknesses of these approaches are very different, and deserve further attention in future research. When the trend seems to be toward globally integrated HRM-systems, at least within companies with global strategies, clearly more research is needed on global HRM solutions concerning all aspects of HRM.

\section{References}

Bass, B.M./Burger, P.C. (1979): Assessment of Managers: An International Comparison, New York, The Free Press. 
Beechler, S./Yang, J.Z. (1994): The transfer of Japanese-style management to American subsidiaries: contingencies, constraints, and competencies, in: Journal of International Business Studies, 25, 467-492.

Birch, N./Pooley, J. (1995): Changes in Russian Quality Management Practices from 1989 to 1992, in: Management International Review, 35, 219-239.

Björkman, I./Ehrnrooth, M. (1999): HRM in Western Subsidiaries in Russia and Poland, in: Journal of East-West Business, 5 (3).

Black, J.S./Ulrich, D. (1999): The new frontier of globar HR, in: Joynt, P./Morton, P. (eds.): The global HR manager. London: Institute of Personnel and Development.

Brake, T. (1997): The Global Leader. Critical Factors for Creating the World Class Organization, Chicago: IRWIN Professional Publishing.

Brake, T. (1999): The HR manager as global business partner, in: Joynt, P./Morton, P. (eds.): The Global HR Manager. London: Institute of Personnel and Development.

Dowling, P.J./Welch, D.E./Schuler, R.S. (1999): International Human Resource Management: Managing People in an International Context. 3rd ed. Cincinnatti, OH: South Western College.

Edwards, P.K./Ferner, A./Sisson, K. (1996): The conditions for international human resource management: Two case studies, in: International Journal of Human Resource Management, 7 (1), 20-40.

Evans, P./Pucik, V./Barsoux, J. (2002): The Global Challenge. Frameworks for International Human Resource Management. Boston, McGraw-Hill.

Ferencikova, S. (2000): Ten years later: A comparative perspective on HRM issues in foreignaffiliated firms in CEE (case of Slovakia), in: Journal for East European Management Studies, 4.

Ferner, A. (1997): Country of origin effects and HRM in multinational companies, in: Human Resource Management Journal, 7 (1), 19-37.

Ferner, A./Quintanilla, J. (1998): Multinationals, National Business Systems and HRM: The enduring influence of national identity or a process of 'Anglo-Saxonization', in: International Journal of Human Resource Management, 9 (4), 710-731.

Frederick, W.R./Rodrigues, A.F. (1994): A Spanish Acquisition in Eastern Germany: Culture Shock, Journal of Management Development, 13, 42-48.

Garrison, T./Artemyev, A. (1994): Managing People in Russia, in T. Garrison and Rees, D. (eds.) Managing People across Europe. Oxford: Butterworth-Heineman.

Gooderham, P.N./Nordhaug, O./Ringdal, K. (1999): Institutional and rational determinants of organizational practices: Human resource management in European firms, in: Administrative Science Quarterly, 44 (3), 507-531.

Gurkov, I./Kuz'minov, Y. (1995): Organisational Learning in Russian Privatized Enterprises. The Beginning of Strategic Change, in: International Studies of Management \& Organisation, 25, 91-117.

Hammerly, H. (1992): Matching global strategies with national responses, in: The Journal of Business Strategy, March/April, 8-12. 
Hofstede, G. (1985): The Interaction Between National and Organizational Value Systems, in: Journal of Management Studies, 22 (4), 347-357.

Johansson, J.K. (2000): Global Marketing: Foreign Entry, Local Marketing \& Global Management. Boston, MA: Harvard Business School Press.

Kraatz, M.S. (1998): Learning by association? Interorganizational networks and adaptation to environmental change, in: Academy of Management Journal, 41 (6), 621-643.

Lindholm, N./Tahvanainen, M./Björkman, I. (1999): Performance appraisal of host coutry employees: Western MNEs in China, in: Brewser, C./Harris, H. (eds.): International HRM. Comtemporary Issues in Europe. London: Routledge.

Longenecker, C.O./Popovski, S. (1994): Managerial Trials of Privatization: Retooling Russian Managers, in: Business Horizons, 37, 35-43.

Nasierowski, W. (1996): Emerging Patterns of Reformation in Central Europe: The Czech Republic, Hungary, and Poland', in: Journal of East-West Business, 2: 143-171.

Odenwald, S.B. (1993): Global Training: How to Design a Program for the Multinational Corporation. Homewood, Illinois: Business One Irwin.

Pucik, V. (1992): Globalization and Human Resource Management, in: Pucik, V./Tichy, N.M./Barnett, C.K. (eds.): Globalizing Management. Creative and Leading the Competitive Organization. New York: John Wiley \& Sons Inc.

Puffer, S.M./McCarthy, D.J. (1993): Soviet Managers View Organisational Change in Large State Enterprises, in: Journal of Organisational Change Management, 6, 6-23.

Ronen, S. (1986): Comparative and Multinational Management. New York: John Wiley \& Sons.

Rosenzweig, P.M./Nohria, N. (1994): Influences on human resource management practices in multinational corporations, in: Journal of Business Studies, 25, 229-251.

Segal-Horn, S. (1996): The limits of global strategy, in: Strategy \& Leadership, November: 12-17.

Schneider, S.C. (1988): National vs. Corporate Culture: Implications for Human Resource Management, in: Human Resource Management, 27 (2), 231-246.

Schuler, R./Dowling, P.J. / De Cieri, H. (1993): 'An integrative framework of strategic international human resource management, in: International Journal of Human Resource Management, 4 (4), 717-764.

Scullion, H. (1999): International HRM in medium-sized MNEs: Evidence from Ireland, in Brewser, C. and H. Harris (eds) International HRM: Comtemporary Issues in Europe. London: Routledge.

Scullion, H./Starkey, K. (2000): In search of the changing role of the corporate human resource function in the international firm, in: International Journal of Human Resource Management, 11(6), 1061-1081.

Stroh, L./Caligiuri, P.M. (1998): Increasing global competitiveness through effective people management, in: Journal of World Business, 33(1), 1-16.

Suutari, V. (2002): Global leader development: An emerging research agenda, in: Career Development International, 7 (4), 218-233. 
Suutari, V./Riusala, K. (2000): Operating in 'economies in transition'- Adjustment and management issues faced by Finnish expatriate managers in CEE, in: Finnish Journal of Business Economics, 49 (1), 87-107.

Svensson, G. (2001): 'Glocalization' of business activities: a 'glocal strategy' approach, in: Management Decision, 39 (1), 6-18.

Torraco, R.J./Swanson, R.A. (1995): The strategic role of human resource development, in: Human Resource Planning, 18 (4).

Walsh, J. (2001): Human resource management in foreign-owned workplaces: evidence from Autralia, in: International Journal of Human Resource Management, 12 (3), 425-444. 